One last remark is suggested by the ornissions from the exhibition. It is to bo hoped that the Post Office, the British Broadcasting Corporation, and the Radio Manufacturors Association, will not forget that the situation in respect of the highest-quality broadcasting is not yet hopeloss.
'The very qualities which may render the ultrashort wave-bands suitable for television working are tho qualities roquired for very high-quality musical reproduction. Channels should be reserved for services of this character before the existing state of congestion in the medium-wave bands has ostablished itself in these still open bands.

\title{
The Welsh Plant Breeding Station, Aberystwyth
}

$\mathrm{I}^{\mathrm{N}}$ response to numerous requests, the Welsh Plant Breeding Station, Aberystwyth, has issued a booklet, price 3s., entitled "An Account of the Organisation and Work of the Station from its Foundation in April 1919 to July 1933". 'Tho publication describes in an ominently readablo form tho general principles governing the work of the Station and the lines upon which it is organised and functions. 'Though not intended to be a precise guide to the experiments, it should prove invaluable to visitors and others desirous of a real insight into the general aims underlying the work, the methods employed and the difficulties encountered.

From tho outset, tho policy has been to concentrate all researches on one main problem, namely, grass. land improvement, though this question is necessurily studiod from a number of aspects the chief of which are plant breeding of herbage crops and trials relativo to their seed production, the improvoment and managoment of ordinary farm grasslands and hill grazings, while plant breeding with oats and wheat and invostigations into plant diseases form necessary complements to the central problem.

The breeding of the more important herbage plants, as porennial ryo grass, white clover and cocksfoot, however, is the pivot upon which the work turns as it is by such characters as leafiness, persistence and flowering habit, factors found to be associated with clearly defined types, that the agricultural value of the herbage is determined. Tho safeguarding of truly authenticated stocks, and the best means for their distribution, ure further problems awaiting solution, and the co-operation of the seed trade, farmers' societies and individual farmors has already been enlisted in the latter cause.

In this connexion a plea is put forward for the foundation of somothing in the naturo of a British or Imperial Seed Production Co., which would be a properly conceived and controlled organisation, acceptable alike to the seed trade and the farmer, and competent to produce the right kind of sceds, sufficiently cheaply and adequately authenticated. The far-reaching nature of the term 'managoment' is fully brought out. The importance of the choice of the seeds mixture, tho uso of rotational grazing, and the significance of differences in yield, productivity, carrying capacity and nutritive value of the various types of herbago are discussed in the light of experimontal evidence.

The necessity for ploughing old pasturos prior to re-sowing has entailed a study of the oat plant, as this makes an excellent first crop after grass. Broeding experiments havo been carried out with the view of finding strains particularly suited to theso poor conditions; hardiness and good standing ability being the chief requisites.

Tho work on rough and hill grazings is of particular interest considering the necessity for making the best use of all availablo grassland at the present time. Climate has not been found to be such a limiting factor to the improvernent of hill pastures as had previously been thought, and after a preliminary cultivation by means of a scratching or ploughing operation, a sowing combined with a manurial dressing has proved of immense value. Wild white clover (preferably assisted by inoculation) is the most important species to include in a seeds mix ture for this purpose and, among the grasses, Yorkshire fog and sweet vernal grass have given particularly promising results.

The extent to which the work of the Station has boen helped by the neighbouring county agricultural organisers, landowners and farmors is evidence of the real practical valuo of the investigations being carried on. Tho publication of this booklet cannot fail to increase and widen the interest taken in grassland management as a whole, and in the methods by which our knowledge of the subject is being extended at Aberystwyth in particilar.

\section{The Cape Observatory}

CCIENCE PROGRESS for July contains an

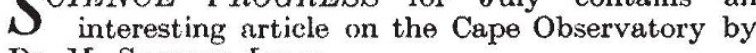
Dr. H. Spencer Jones.

Rev. F. Fallows was tho first director and commenced work in 1821. He worked under great difficultios, the site being inhospitable, the instruments badly made, the assistanco allowed to him hopelessly inadequate; he died in 1831 at the early age of forty-two years. It may be remarked that the amenities of tho site have now been greatly improved, the bare rock having been covered with a good depth of soil, trees planted to shelter the instruments from wind, and a good water-supply laid on.

Henderson was director for only one year, but did good work in that time; inter alia he detected the large parallax of $\alpha$ Centauri.
Maclear was director in 1834-1870. In his early days there ho enjoyed the companionship of Sir J. Horschel, who established an observatory at Feldhausen in order to extend his fathor's survey to tho southern hoavens. Maclear mado an immense number of observations, but their reduction was delayed owing to insufficient staff. It was completed after his rotiroment by his successor, E. J. Stone. Ho in turn was succeeded by Sir David Gill in 1879. Tho great comet of 1882 was tho accidental occasion of detecting the value of photography for determining the position of stars. This led both to the formation of the Cape Photographic Durchmusterung and to the great Astrographic Catalogue of the entiro heavens.

The Capo Zone has been rephotographed under Dr. Spencer Jones, and comparisons of the earlier 
and later plates will shortly yield proper motions of about 40,000 stars. The average time-interval between early and recent plates is 25 years.

Gill made a determination of the solar parallax from obscrvations of Iris, Victoria and Sappho: the resulting value $8 \cdot 804^{\prime \prime}$ was nearly identical with that deduced by Hinks from the Eros-opposition of 1901 . The Cape Observatory took a larger share than any other in the observations of Eros in 1931: it is expected that the resulting value of the parallax will be accepted as definitivo for a long period. The McClean 24-in. equatorial was presented to the Capo Observatory in 1900 and was used for stellar spectroscopy until 1926, the last spectrograms taken with it being of Nova Pictoris. They sufficed to provo a rapid expansion in the outer layers of the star, while the effective temperature remained nearly constant.

The 24-in. is now being used for stellar parallax work, 500 parallaxes having already been determined with it.

The article is accompanied by reproductions of urtistic pencil drawings : one, a general view of the Observatory and the surrounding mountains; the other, the dome of the 7-in. heliometer.

\section{University and Educational Intelligence}

Cambridge.-Dr. M. Born has been appointed University lecturer in the Faculty of Mathematics.

The Frank Smart studentship in botany will bes vacant on October 1. Any graduate of the University is eligible for the studentship provided that not more than fourteen terms have elapsed after his first term of residence. The successful candidate must devote himself to research in botany under the direction of the professor of botany. The value of the studentship is $£ 200$ per unnum and names of candidates must bo submitted to Prof. A. C. Soward at the Botany School on or beforo October 2 .

London.-Prof. H. W. Florey, Joseph Hunter professor of pathology in the Lniversity of Sheffield, whose appointment to tho Sir William Dunn chair of pathology tenable at Guy's Hospital Medical School wiss announced by the University of London on July 27 , is unable to accept the appointment.

The following degrees have recently been awarded: D.Se. in zoology to Benjamin Dawes (recognised teacher at King's College) for six works on the development of the vertebral column in marnmals and on the food requirements in the plaice; D.Sc. (Engineering) to Robert O. Boswall (King's College) for seven works on lubrication; D.Se. (Engineering) to Edward Hughes (private study) for published work on (1) heating of electrical machines, (2) testing of magnetic materials, (3) effect of harmonics on power-factor improvement, (4) testing of ceiling fans.

Tere fact that the School Certificate has, since its inception somo fourteen years ago, assumed a prodominating influence over secondary education in Great 13ritain, has been stressed several times in these columns. As stated in NATURE of Fobruary 18, p. 218, all secondary and public schools have como under its influence; instead of following the curriculum, it determines what lines the curriculum shall adopt ; and, worst of all, in very many cases, it is a matriculation qualification. In other words, the
School Certificate examinations, instead of assessing the educational standing of a pupil at the age of about sixteen years, is too frequently used to decide his qualifications for entrance to a University. In the summer of 1931 , nearly 67,000 candidates sat for the School Certificate examination. Considering the small percentage of that number who had any obvious desire at all to carry on their academic studies and read for a Liviversity degree, the char. acter of the School Certiticate examination for the rank and file scoms quite unsuitable." It is clearly not what it should be; that is, a school leaving certificate assessing the qualifications of pupils for the edification of not so much the University authorities as for business, commercial and professional bodies who require the services of such pupils. It is with satisfaction, therefore, that we read in "Education in 1932 " being the report of the 13oard of Education published in Juno of this year (H.M. Stationery Office, $3 s .6 d$. net) that the Secondary Schools Examinations Council agrees with the investigators of the School Certificate Examinations in their recom. mendation that the Sehool Certificute examination should no longer be accepted by the Universities as an alternative to their own matriculation examinations; and that it should not bo permissible for a pupil to take an external matriculation examination unless he is a genuine candidate for admission to a University. This is one step towards estublishing the School Certificate and the matriculation as two soparate examinations, each with its necessary but distinctly different function to perform.

THE recently issued annual report of University College, Iondon, includes an account of a notable expansion rendered possible by the acquisition of a large area to the south of its present site. This fulfilment of a long-cherished aspiration of the College authorities was achieved in co-operation with the Carnegie United Kingdom 'Trustees, by whom a part of the area is to be used for the purposes of the National Central Library and the Library Association. A prominent feature of this expansion is the rehousing of the Department of Zoology, now to be reorganised, with aderuate equipment as a Department of Zoology and Comparative Anatomy on a seale of national importance. Student eurolments of the session 1931-32 show a decrease in the number of evening students due to the London County Council's discontinuance of awards of free places in tho evening schools of geography, history and phonetics in favour of a now systern of grants to individual students. The number of vacation students also decreased owing to phonetics and librarianship vacation courses not being held. The number of other students, 2,705 , is almost the same as in the preceding year, 2,709. Postgraduato and reseurch students numbered 465, an increase of 17. A table giving the geographical distribution of students shows that 57 per cent wero from homes within thirty miles from the College, 24 por cent from elsewhere in the British Isles, 10 per cent from the rest of the Empire and 9 per cent from other parts of the world. Those from India numbered 151, from Gormany 40, from the United States 39, from Australia and New Zealand 34, from South Africa 23, from Scandinavia 23, from France 21 and from Switzerland 21. Appended to the roport are reprints of speeches at tho summer assombly and a list of 637 original publications from the various departments of the College. 